\title{
Précis of Frustration Theory: An Analysis of Dispositional Learning and Memory
}

\author{
ABRAM AMSEL \\ University of Texas, Austin, Texas
}

\begin{abstract}
This is a précis of a book on frustration theory, whose explanatory domain includes a family of phenomena that have been summarized by the terms dispositional learning and memory-systems that ordinarily have a long-term historical etiology, and in which the learning is relatively reflexive and the memory implicit and not strongly episodic. The book is an attempt, in the context of stimulusresponse learning theory, to present in some detail an animal-based model of frustration as it is applied to a limited-but still large-number of these experimentally established phenomena (perhaps the largest number organized by any one such theory). These bear some resemblance to equivalent phenomena in humans, to which the descriptive terms arousal, suppression, persistence, and regression have been applied. An explicit caveat is that this is a book on one particular theory of frustration and not a book on frustration theories. Whereas it does address other theories of frustration, its main purpose is to review a line of theorizing and experimental research that has evolved over some 40 years: an analysis of the status of the concept of frustration in learning theory.
\end{abstract}

In the history of the scientific study of learning and memory, a number of terms have been used to describe abstract experimental paradigms that purport to represent different mechanisms of learning. In the book discussed here, I refer to several of these, the most fundamental being classical (Pavlovian) conditioning and instrumental (Thorndikian) learning. These two are central to understanding the phenomena I will call the rewardschedule effects. These phenomena depend on a variety of interactions between reward and nonreward, and they are the basis for a family of generalizations known as frustration theory.

My major thesis, in general terms, is that there is inherent in such reward schedules the buildup of primary frustration, defined simply as a temporary state that results when a response is nonreinforced (or nonrewarded, in more neutral language, in the appetitive case) in the presence of a reward expectancy; that a learned or anticipatory form of this temporally labile state, based on classical conditioning, can be elicited by an originally indifferent or neutral cue; that this conditional form of frustration, like other learned states, is permanent, at least for a given situation; and that, together, the primary (unlearned) and the secondary (learned) forms can account for a number of important processes in the dynamics of instrumental behavior, summarized by four familiar behavioral concepts: arousal, suppression, persistence, and regression. These four concepts define

I am greatly indebted to Elizabeth Capaldi and Michael Rashotte for their valuable suggestions for revision of an earlier draft of this précis. Correspondence should be addressed to A. Amsel, Department of Psychology, Mezes 330, University of Texas, Austin, TX 78712 (e-mail: amsel@psyvax.psy.utexas.edu). what I regard as the end points of dispositional learning, a term that bears a strong resemblance to the term dispositional memory, which was proposed by Thomas (1984), who differentiates it from representational memory. It is in this sense that frustration theory is an analysis of dispositional learning and memory.

The Random House dictionary defines dispositions as "aspects and habits of mind that one displays over a long time." A synonym provided in most dictionaries is "temperament," and references are always made to "personality." An important mechanism in what I have called dispositional learning is the interplay between rewards and frustrative nonrewards, particularly when these two consequences result from what is essentially the same behavior. Added to what may be the effects of inherited behavioral tendencies, dispositional learning determines the general, long-term temperamental characteristics of individuals, such as tendencies to approach or to avoid, to persist or to desist. In the explanatory domain of frustration theory, these include tendencies to be aggressive or defensive, to overreact or not to overreact, and to alter or not to alter the direction and/or intensity of behavior when rewards are withheld, delayed, or reduced. In these terms, dispositional learning can be identified in all mammalian species that have been studied, including humans.

The inclusion of the word "memory" in the title of the book requires some clarification. It is in a sense made necessary by a number of similar distinctions made, primarily by neuropsychologists of human memory. The common thread that runs through these distinctions is that there are two fundamental kinds of memory that depend on different kinds of "encoding"- that is to say, on the different ways in which these memories are formed or learned. Table 1 reproduces a table from a book by 
Table 1

Two Kinds of Memory

\begin{tabular}{ll}
\hline Fact memory & Skill memory \\
Declarative & Procedural \\
Memory & Habit \\
Explicit & Implicit \\
Knowing that & Knowing how \\
Cognitive mediation & Semantic \\
Conscious recollection & Skills \\
Elaboration & Integration \\
Memory with record & Memory without record \\
Autobiographical memory & Perceptual memory \\
Representational memory & Dispositional memory \\
Vertical association & Horizontal association \\
Locale & Taxon \\
Episodic & Semantic \\
Working & Reference \\
\hline
\end{tabular}

From Memory and Brain (Figure 43, p. 169), by L. R. Squire, 1987, New York: Oxford University Press. Copyright 1987 by Oxford University Press. Adapted by permission.

Squire (1987) that lists a number of these distinctions, including Thomas's, between these two kinds of memory. The first five items, among which there is little if any difference, are: fact versus skill, declarative versus procedural, memory versus habit, explicit versus implicit, and knowing that versus knowing how. Among these pairs of items, the common theme is that the first in each case refers to the encoding into memory of an event or episode, usually on the basis of a single exposure of which the individual is fully, "cognitively" awarememory with record, in terms of the distinction in the ninth pair in the table. The second item in each case refers to a kind of "memory" that is the product of dispositional learning; it is the product of learning requiring many exposures or trials and in which awareness play little or no part-memory without record, in the words of the second part of the ninth pair in the table. Learning theorists have generally not referred to the retention of this kind of tendency or association as memory, mainly because they have regarded such associations as being relatively "permanent," and subject to apparent reduction in strength only through active processes-nonreinforced extinction or counteracting (conflicting) associative tendencies.

In making the memory versus habit, or "knowing that" versus "knowing how" distinction, Mishkin and Petri (1984) actually characterize the left-hand item in each case as Tolmanian and the right-hand item as Hullian, a distinction, presumably, between Tolman's cognitive maps and Hull's habits. A further characterization of the metatheoretical orientation of this book, then, is that, dealing as it does with dispositional learning, it is very much more to the right-hand side than the left-hand side of the items in Table 1; it is much more a model of learning that is implicit, occurs without awareness, and is reduced only by counteracting mechanisms, rather than memory based on a single attention-engaging episode, and subject to decay with the passage of time. The former, and not the latter, is then my meaning of "memory."

\section{BEHAVIORISM AND NEOBEHAVIORISM}

Although my theorizing in this book alludes to mechanisms like anticipation and expectancy, which can obviously be characterized as cognitive, the constructs are those associated with neobehaviorism. I have argued (Amsel, 1989) that this approach is at the same time more analytical and more constraining than the more mentalistic cognitive approaches, and that a little constraint goes a long way in theorizing about behavior and its determinants.

In light of the neuroscientific emphasis of some of our more recent work (see chapters 7 and 8), the position I have taken can be characterized as a version of "liberalized" stimulus-response (S-R) neobehaviorism, the term N. E. Miller (1959) used for his own brand of S-R psychology. In most respects, however, this book is in the lineage of the neobehaviorism of C. L. Hull-with its emphasis on learned and unlearned S-R associations, adaptiveness of behavior, and concepts derived from physiology; with its admonitions to guard against subjectivism and anthropomorphism; and with its preference for $\mathrm{S}-\mathrm{R}$ analyses of terms such as knowledge, anxiety, purpose, and anticipation, particularly in his famous Psychological Review papers, starting in 1930 (see Amsel \& Rashotte, 1984).

If there is nowadays a focus in the disagreement between the positions of the neobehaviorists and the cognitivists who work in the learning and behavior of rats and pigeons, it is that the former invent constructs to explain behavior, whereas for the latter, behavior is, in itself, relatively unimportant, except as a "window on the mind." It is also the case, however, that the disagreement between neobehaviorism and what I will call "animal cognitivism" is not only between the stimulus-response and the cognitive explanatory languages, but also to a large extent between the experimental topics that each addresses (Amsel, 1989). I address these differences in the next section.

\section{NEOBEHAVIORISM: HABITS, NEEDS, INCENTIVES, AND BEHAVIOR}

The first shots in the "cognitive revolution" in Psychology, some 30 years ago, were fired not by animal cognitivists, but by people who wanted to draw firmer lines between investigations involving humans and animals as subjects. The neocognitivists were, of course, concerned with processes they regarded as primarily human-remembering and forgetting of verbal material, processing of information, perception, simulation of human problem solving by computers, formation and identification of concepts, reading, language, and so on. These revolutionists of the 1960 s seemed to have forgotten that 
many if not most of the investigators who were identified as learning theorists, and who worked with animals, were less interested in the cognitive and intellectual abilities of the animals they chose as models than in the more basic learning processes that occur in Pavlovian conditioning and instrumental (Thorndikian) learning, and in basic motivational or need systems. In short, many of these investigators were developing animal models of the perhaps more procedural or habit ("dispositional" in my sense) systems that can be thought to operate not only in adult humans, but in early human development and in animals as well. Both Hull and Tolman, two of the major learning theorists of the $1930 \mathrm{~s}$ and 1940 s, introduced into psychology theoretical systems that had as their main concerns the identification of the factors that contributed to the formation of habits and goal expectancies, as they interacted with the complementary concepts of need, drive, and demand. Hull, for example, was tremendously preoccupied with the mechanisms of adaptation and survival. This preoccupation can be found even in his most formal theorizing-for example, in Principles of Behavior (1943); his earlier seminal papers showed this interest even more clearly.

The next generation of learning theorists, among them H. F. Harlow, N. E. Miller, O. H. Mowrer, B. F. Skinner, and K. W. Spence, carried on a tradition of experimental research and theory in which the aim was to understand the basic associative and motivational processes by studying and understanding these processes in animals. (Or so, at least, it has seemed to me.) True, Skinner's work with pigeons has given us a tremendous increase in our understanding of the ways of the pigeon; but obviously, as his later papers and speeches show, Skinner was interested in pigeons not as an ethologist might be, but more abstractly, as an animal model for the experimental analysis of human behavior. Harlow's later work was carried out primarily with monkeys and other nonhuman primates, and this work has contributed greatly to our knowledge of emotional-affectional systems in primates. But, clearly, Harlow's primary intention and purpose was to understand these systems in people. As I suggested over three decades ago (Amsel, 1961), at about the time at which the cognitive revolution began, one of the characteristics of most of the American learning theorists who had worked with animals in the preceding quarter century (or more) was that they were not interested in the animals they were studying in the way a naturalist is, but rather as "preparations" for developing hypotheses about associative and motivational-emotional processes in higher animals in general and in humans in particular. For this reason, applications of learning theory to personality and psychopathology, to fear and anxiety, to conflict and frustration, to dispositional learning and memory came from research on animals, not from work in human learning. This book and the work on frustration theory are clearly in this tradition.

\section{DEVELOPMENTAL PSYCHOBIOLOGY, AND LEVELS OF FUNCTIONING IN DISPOSITIONAL LEARNING}

One direction animal-based learning theory has taken (the other being toward animal cognition) is that toward behavioral neuroscience or psychobiology, and the later chapters of this book suggest that this is a direction toward which the developmental work on dispositional learning and memory has moved. If one approaches the study of learning and memory from an ontogenetic (or phylogenetic) perspective, or from the perspective of studying brain-damaged animals and people, it is easy to accept the view that there are "lower" and "higher" levels of processing in learning and memory and that, as the neuropsychologists of learning and memory have recognized, the lowest levels reside even in the nonintact human adult.

Using simple behavioral techniques, and concepts derived from frustration theory, we have been able to provide developmental data on the order of emergence of a sequence of reward-schedule effects in ontogeny, a sequence that has been taken to represent stages in the development of dispositional learning and memory (Table 2). In chapter 7, I examine the ontogeny of a number of these behavioral effects. Here are some examples: At 11 days of age, rat pups can learn to discriminate the presence or absence of reward on the basis of a singlealternating pattern-approaching a goalbox rapidly on odd-numbered, rewarded trials and greatly suppressing

Table 2

Age of First Appearance of Various

Reinforcement-Schedule Effects

Effect Age

Successive acquisition and extinction

(Amsel, Burdette, \& Letz, 1976)

Single patterned alternation (PA)

(Stanton, Dailey, \& Amsel, 1980)

$\leq 10$ days

Partial reinforcement extinction (PREE)

(Chen \& Amsel, 1980a, 1980c;

Letz, Burdette, Gregg, Kittrell, \& Amsel, 1978)

Variable magnitude of reinforcement extinction

(VMREE)(Chen, Gross, \& Amsel, 1981)

Partial delay of reinforcement extinction (PDREE)

(Chen, Gross, \& Amsel, 1981)

Partial reinforcement acquisition (PRAE)

(Chen, Gross, Stanton, \& Amsel, 1980)

Magnitude of reinforcement extinction (MREE)

(Burdette, Brake, Chen, \& Amsel, 1976;

Chen, Gross, \& Amsel, 1981)

$\leq 11$ days

Successive negative contrast (SNC)

(Chen, Gross, \& Amsel, 1981;

Stanton \& Amsel, 1980)

12-14 days

16-18 days

16-18 days

$18-20$ days

$20-21$ days

Slow responding (DNC)

(Chen, Gross, Stanton, \& Amsel, 1981)

$25-26$ days

From "Developmental Psychobiology and Behavior Theory: Reciprocating Influences," by A. Amsel, 1986, Canadian Journal of Psychology, 40, p. 315 . Copyright 1986 by the Canadian Psychological Association. Adapted by permission. 
approach on even-numbered, nonrewarded trials. At this age, they can do this if the time interval between rewards and nonrewards is brief $(8 \mathrm{sec})$ but not if it is longer $(30-60 \mathrm{sec})$. As animals grow older, their developing memory allows them to make these patterned responses over longer and longer intertrial intervals (ITIs). On a partial reinforcement (PRF) schedule, a quasirandomly ordered schedule of intermittent rewards and nonrewards, 14-day-old pups (but not 11-day-olds) learn to be relatively resistant to extinction (persistent) compared with pups on a continuous reinforcement (CRF) schedule. By 18 days of age, the magnitude-of-reinforcement-extinction effect (MREE) is first seen: extinction is faster, with concomitant heightened frustration, after CRF training with large than with small rewards. At about 25 days, animals shifted from a largesized to a small-sized reward, compared with animals run to the small reward from the outset, show an emotionally related depression in performance (called successive negative contrast, SNC); younger animals do not show this effect of downsizing reward magnitude.

In adult rats, some of these behavioral, "emotional" reinforcement-schedule effects and several others have been shown to depend on the integrity of portions of the limbic system and adjacent cortical areas, particularly the hippocampal formation with its connections to the septum and entorhinal cortex. In chapter 8 , I examine the parallel developments of aspects of hippocampal function and the ontogeny of the reward-schedule effects. Portions of this system that appear to be important in learning and memory show a particularly rapid rate of development in late prenatal and early postnatal stages in the rat. We can therefore begin to ask such questions as these: What are the developmental brain changes that are related to the demonstrated stages of development of learning and memory? How do lesions in this system affect the emergence of the behavioral effects from which learning and dispositional memory are inferred? And if lesions eliminate effects that occur early in infancy, is there a recovery of these functions later in development? Conversely, do the kinds of training that are required for the earliest manifestation of these effects on learning and memory affect neuronal plasticity? Do they induce acceleration or retardation in some of the structural landmarks of brain development - cell size and number, dendritic branching, synapse formation, neurotransmitter release - and how are these changes, in turn, related to the accelerated or retarded appearance of the later behavioral effects? How do teratogenic treatments, such as exposure to alcohol in utero, or early postnatal exposure of postnatally arising hippocampal granule cells to $\mathrm{x}$-irradiation affect the ages of appearance of normal capacity to learn and remember? It should be clear, however, that none of these questions could be asked until the theory and research on what I have called dispositional learning, outlined in chapters 3,4 , and 5 of the book, had reached a certain stage of maturity.

This book deals with the psychodynamics and the developmental psychobiology of dispositional learning from a neobehavioristic orientation: Frustration theory is an attempt to explain and to predict - to integratea number of phenomena of instrumental learning that have in common their dependence on the properties of frustrative reward, which in turn depends on conditioned expectancies and the failure of their confirmation. It is an animal model that may contribute to a more general understanding of the development in humans of such specific problems as abnormalities in emotional affect, attention deficits with hyperactivity, deficits in the capacity to suppress behavior and form discriminations, and deficits or excesses of persistent or perseverative behavior.

\section{EXTERNAL AND INTERNAL STIMULUS CONTROL}

As we discuss the characteristics of dispositional learning and the various reward schedules under which it occurs, it becomes plain that the environmental control of this kind of learning is both external and internal to the learner, and that in some of the cases to be considered, the internal environment is the much more important of the two. The possible exception to this assertion is the case of discrimination learning in which there are differential external stimuli controlling differential responding, but, as chapter 5 illustrates, even here internal cues are involved. In most cases of dispositional learning, however, the apparatus employed is a simple uniform runway, the motivation is hunger or thirst rising out of food or water deprivation, and no differential external cues are involved. The interoceptive control that then comes to the fore arises, in these reward-schedule cases, entirely out of the nature of the rewards, nonrewards, reduced rewards, and delayed rewards that occur at the termination of an instrumental response.

These internal stimuli are of two kinds. One is a direct consequence of what has happened on the last learning trial, the direct feedforward from trial $N$ to trial $N+1$, which can be characterized as a short- or intermediateterm trace or memory of the last goal experience that controls the next. This has been the interoceptive-stimulus mechanism featured in many of Capaldi's (e.g., 1967) explanations of reward-schedule learning, and, in his view, these stimuli can account even for relatively longterm memorial consequences of reinforcement and nonreinforcement.

The second kind of guiding internal stimulus also depends on goal events - the reward and the frustrative nonreward - but in a different way. In this second case, the response-produced internal stimuli arise out of classically conditioned internal responses or goal "expectancies," based on the goal events on all preceding trials. These are the hypothetical, internal, classically conditioned responses and feedback stimuli that Hull (1931) called fractional anticipatory goal responses $\left(\mathrm{r}_{\mathrm{G}}-\mathrm{s}_{\mathrm{G}}\right)$, or "pure stimulus acts." The kind of theorizing that has involved such interactions has been called "conditioning-model theory" (Lachman, 1960), and it repre- 
sents a strategy I have adopted and used in my own theorizing. Others have investigated these interactions (mainly in aversive conditioning) under such headings as "two-process theory" (Gray, 1975; Rescorla \& Solomon, 1967), and "the second learning process" (Trapold \& Overmier, 1972). In this book, the notation that I employ is the Hullian one, but I make no distinctions and see no important differences between this one and the others.

\section{SUMMARY OF THE METATHEORY}

The metatheoretical position of this book can be summarized as follows: It is, as we have seen, a neobehaviorism involving stimuli and responses at both the descriptive and explanatory levels, the S-R theoretical approach being a "liberalized" one in N. E. Miller's (1959) meaning. There is no attempt to avoid coordination of such constructs with physiological states and processes. In this sense, the position is not fundamentally different from early Watson (1919) or even from the Skinner of Behavior of Organisms (1938), in which intermediary constructs like drive, emotion, and reflex reserve were acceptable, and the strength of the latter state was expressed in a series of "dynamic laws" that were clearly and admittedly Sherringtonian. The present position, in this respect, is also close to Hull's in Principles of Behavior, in which allusions to physiology and uses of physiological-sounding constructs (e.g., "afferent neural interaction," "receptor-effector connection") can be found on every other page. Hull (1943) stated his position on the role of neurophysiology in the study of behavior as follows:

There can hardly be any doubt that a theory of molar behavior founded upon an adequate knowledge of both molecular and molar principles would in general be more satisfactory than one founded upon molar considerations alone. But here again the history of physical science is suggestive. Owing to the fact that Galileo and Newton carried out their molar investigations, the world has had the use of a theory which was in very close approximation to observations at the molar level for nearly three hundred years before the development of the molecular science of modern relativity and quantum theory. Moreover, it is to be remembered that science proceeds by a series of successive approximations; it may very well be that had Newton's system not been worked out when it was there would have been no Einstein and no Planck, no relativity and no quantum theory at all. It is conceivable that the elaboration of a systematic science of behavior at a molar level may aid in the development of an adequate neurophysiology and thus lead in the end to a truly molecular theory of behavior firmly based on physiology. (p. 20)

In this regard, my position is more like Hull's and less like Spence's (e.g., 1956), which, in line with his wellknown disagreements with Hull on "physiologizing," tended to avoid physiological-sounding constructs (see Amsel \& Rashotte, 1984). Indeed, in what may have been the last statement of his position on this matter, in a "Pavlovian Conference on Higher Nervous Activity,"
Spence (1961) not only repeated and confirmed his commitment to the discovery of "a set of abstract theoretical concepts" (p. 1188, italics his), but pointed out, with some justification, that on close examination Pavlov's concepts, such as internal inhibition, were of the same sort as his own, and did not refer to any identifiable neurophysiology. In my own case, particularly in chapters 7 and 8 of the present book, there is some identifiable neurophysiology and neuroanatomy.

Another, and perhaps more important, aspect of the metatheoretical orientation of this book is that, while it is Hull-Spence in lineage, it is clearly more in the spirit of the Hull and Spence of the 1930s than of their more formalized, sometimes mathematical treatments. For example, it borrows a great deal more from Hull's earlier theoretical papers (see Amsel \& Rashotte, 1984) than from his more formalized treatment of learning in Principles of Behavior (1943), and more from Spence's famous papers on discrimination learning $(1936,1937$, 1940) than from his more formal treatments (Spence, 1956). As in Hull's early papers and in the work of those who followed in this tradition (e.g., Berlyne's [1960, 1964] analyses of curiosity and thinking; Miller's [1944, 1948] analyses of conflict and displacement; Mowrer's [1939] analysis of anxiety), terms such as "anticipation" and "expectancy" are not avoided; however, when they enter into theoretical statements, they are reduced to their unambiguous meaning as classically conditioned responses and to the S-R notation, so that they can find integration with other constructs of the theory.

\section{OUTLINE OF THE BOOK}

This book can be divided into four parts. The first part includes the kind of introductory material I have already presented in chapter 1 , and chapter 2 , which reviews the notation of the motivational and associative constructs of stimulus-response neobehaviorism in which the theoretical content of this book is cast. The second part consists of chapters $3,4,5$, and 6 . Chapter 3 introduces frustration theory and provides an overview of its explanatory scope. Chapter 4 sets the stage for the later chapters on development by providing evidence from a large number of experiments on the generality and durability of persistence, which is learned during a specific series of intermittent rewards and frustration and may become quite general and permanent in dispositions to control the animal's behavior much later in life. As we shall see, perhaps the crucial mechanism in this dispositional learning can be conceptualized as the acquisition of conditioned or anticipated frustration and its association with some specific mode of responding - for example, persistent or desistant; aggressive or regressive. Chapter 5 provides a frustration theory account of discrimination learning involving questions such as these: How are discriminations formed? How can their acquisition be facilitated or retarded by prior dispositional learning experience? Chapter 6 is a summary of what has gone before, giving special emphasis to alter- 
Table 3

Steps in the Psychobiological Study of Related Behavioral Effects

1. Observe and describe a number of apparently related behavioral effects.

2. Develop a conceptualization of these effects in terms of empiricalconstruct theory.

3. Study these effects ontogenetically for their presence or absence at various developmental stages, and for the order of their first appearance.

4. Study these effects for their presence or absence in relation to the presence or absence of portions of, or activities of, their presumed neural substrate.

5. Relate the order of appearance of the effects to the developing neural substrate.

6. Modify empirical-construct theory on the basis of findings from 4 and 5 .

native analyses of theories of the partial reinforcement extinction effect. The third part of the book, chapters 7 and 8 , covers developmental and neurobiological material. Chapter 7 provides a developmental analysis of a body of research on the ontogeny of conditioning and learning in the infant rat and on the ontogeny of dispositional learning, with special emphasis on the sequence of appearance in ontogeny of a number of rewardschedule effects. In chapter 8 , there is a discussion of the parallel development of the putative neuroanatomical and neurophysiological substrates of this sequence of behavioral effects.

The fourth, concluding part of the book comprises chapters 9 and 10 . Chapter 9 is a reprise of the content of the book in which I attempt to demonstrate that, to a reasonable extent, the overall strategy of the book, summarized in the statements that are shown in Table 3, have been addressed and developed in the previous eight chapters. Chapter 10 addresses possible human applications of frustration theory.

\section{THE CONCEPT OF FRUSTRATION IN PSYCHOLOGICAL THEORY}

At the beginning of chapter 3, to provide some background for the experimental study of frustration, and to emphasize again the fact that this is not a book on frustration theories, I point to a book by Lawson (1965), which can be regarded as a follow-up of an excellent earlier review of the state of the experimental study of frustration until about 1938, in a symposium at the meeting of the American Psychological Association (Rosenzweig, Mowrer, Haslerud, Curtis, \& Barker, 1938). Lawson reviews attempts to derive a theoretical meaning of frustration from its vernacular usage and then to move from the theoretical meaning to experimental operations. He divides theories of frustration into two kinds: "selfcontained theories" and theories "integrated with general behavior theory." In the first category he places Rosenzweig's $(1934,1944)$ frustration theory; the frustrationaggression hypothesis (Dollard, Doob, Miller, Mowrer, \& Sears, 1939); the frustration-regression hypothesis
(Barker, Dembo, \& Lewin, 1941); and the frustrationfixation hypothesis (Klee, 1944; Maier, 1949, 1956). He points out that none of these theories were particularly linked to or emergent from a more general theoretical position.

Lawson's second category of theories, the "integrated" ones, are identified as the Child and Waterhouse (1952) revision of the frustration-regression hypothesis; Brown and Farber's (1951) treatment of frustration as emotion conceptualized as an intervening variable; and my own (Amsel, 1958) "frustrative nonreward theory." A very important point Lawson makes, and one I have made for my own case, is that the distinguishing characteristics of such theories include their closer alliance to more formal (and more general) behavior theory; the related recognition that these frustration theories involved many independent. variables already familiar from theories of learning; and a growing recognition that "there was no unique overt behavior characteristic of frustration situations" (Lawson, 1965, p. 27).

In the book, I refer to Hull's formal papers on learning theory in the 1930s, in which there are references to frustration, both as an experimental operation in his analysis of the goal gradient in maze learning (erecting a physical barrier against a response; Hull, 1934) and in the form of a specific "frustration hypothesis" in his work on the goal-gradient in children (Hull, 1938). Hull's hypothesis states "that whenever an excitatory tendency is prevented, for any reason, from evoking its accustomed reaction, a state ensues substantially like the experimental extinction or internal inhibition long known to be characteristic of conditioned reactions" (p. 278, n. 10). Hull's concept of frustration stressed barriers rather than nonrewards, and it was never formally incorporated into his own systematic theorizing; however, it remained a peripheral interest of his and of those at Yale who later proposed the frustration-aggression hypothesis (Dollard et al., 1939). The eventual realization of what Lawson called a frustration theory that was "integrated with [Hull's] general behavior theory" came in the 1950s with the Brown and Farber theory, and with my own.

\section{Short History of Frustration Theory}

Both Hull (1952) and Spence (1956) accepted the view that "frustration" (or some other emotional factor) accounts for the incentive contrast effect (Crespi, 1942; Elliott, 1928), a suppression effect that occurs when magnitude of reward is shifted from large to small, but neither provided a detailed account of how frustration might enter into the structure of learning theory. Other researchers had also reported signs of "emotional" upset in animals at the beginning of extinction (e.g., Miller \& Stevenson, 1936; Skinner, 1938), but, again, these observations were never formally incorporated into a more general theory of learning.

In 1951, I conceptualized the role of frustration, and more specifically anticipatory frustration, as a third factor to be added to Hull's (1943) two-factor theory of inhibition, and I applied it to the Elliott-Crespi incentive 
contrast effect. This conceptualization was later extended to cover the partial reinforcement extinction effect (PREE), discrimination learning, and a number of other rewardschedule phenomena (Amsel, 1951, 1958, 1962, 1967, 1986; Spence, 1960; Wilson, Weiss, \& Amsel, 1955). Mine was an extension of the conditioning model approach to include a theory of frustration.

Figure 1, after Amsel and Ward (1965), represents assumptions about the manner in which primary reward $\left(R_{R}\right)$ and frustrative nonreward $\left(R_{F}\right)$ are involved as goal responses in simple instrumental learning. It shows, schematically, the conditioning of anticipatory reward $\left(r_{R}\right)$ and anticipatory frustration $\left(r_{F}\right)$ to the cues of the apparatus or situation $\left(S_{A}\right)$ in the context of instrumental behavior. Shown on the left of the figure is that instrumental responses followed by $S_{R}$ and $R_{R}$ occasion the development of $r_{R}$ (anticipatory reward), which moves forward in the temporal sequence, so that its feedback cues $\left(s_{R}\right)$ become part of the stimulus compound eliciting that instrumental response. When $r_{R}$, through its feedback stimulation, $s_{R}$, shares control of the instrumental response, the behavior can be said to involve appetitive incentive motivation. On the right-hand side of Figure 1, we see that when the incentive motivation of reward $\left(r_{R}\right)$ is operating, and the goal event is nonreward $\left(S_{n o n R}\right)$ instead of $S_{R}$, primary frustration $\left(R_{F}\right)$ results. The presence, in sequence, of both anticipatory reward $\left(r_{R}\right)$ and nonreward $\left(S_{n o n R}\right)$ is, then, the necessary and sufficient condition for the elicitation of primary frustration $\left(R_{F}\right)$. In the presence of $r_{R}$, the unconditioned response to the absence of the unconditioned (nonreward) stimulus, $S_{\text {nonR }}$, is $R_{F}$, which becomes the unconditioned response (UCR) for the conditioning of $r_{F}$ (right-hand side of the figure) to the cues of $\mathrm{S}_{\mathrm{A}}$. This conditioned response of anticipatory frustration $\left(r_{F}\right)$ affects the instrumental response through the action of $\mathrm{s}_{\mathrm{F}}$, presumably in a manner antagonistic to that in which $r_{R}-s_{R}$ affects the instrumental response.

To recapitulate, I proposed in 1951 that, in addition to $I_{R}$ and $I_{R}$, a third factor, anticipatory frustration $\left(r_{\mathrm{F}}-\mathrm{s}_{\mathrm{F}}\right)$, was important to the understanding of a number of nonreinforcement-related effects. This was followed by the demonstration of the frustration effect (FE), taken to be an indicant of the response of primary frustration ( $R_{\mathrm{F}}$; Amsel \& Roussel, 1952), and this demonstration provided a necessary basis (the UCS and UCR) for the conditioning of anticipatory frustration $\left(r_{F}-s_{F}\right)$. Subsequent developments provided accounts of the PREE, the role of nonreward in discrimination learning (Amsel, 1958, 1962), and, later, other paradoxical effects emerging out of the interactions of reward and nonreward in adults and, sequentially, in infants (see Table 2) in a variety of discriminative and nondiscriminative instrumental learning situations.

\section{Properties of Frustration}

In informal terms, the basis of the theory of 1951 was that the replacement of a period of continuous reward by a nonreward, reduced reward, or delayed reward results in the aversive motivational state, primary frustration $\left(R_{F}\right)$. This occurs because the existing $r_{R}-s_{R}$, conditioned by the sequence of rewards, is greater than that which the nonreward, reduced reward, or delayed reward on that trial can support. For example, the strength of $r_{R}-s_{R}$ established with a large reward is greater than that established with small reward. Accordingly, the theory requires that $R_{F}$ occur when a small reward, or in the limiting case, nonreward, is presented after training with a large reward.

The book examines four properties of frustration. The first, unconditioned (primary) frustration $\left(R_{F}\right)$, is a direct reaction to the frustrating event that exerts a tran-
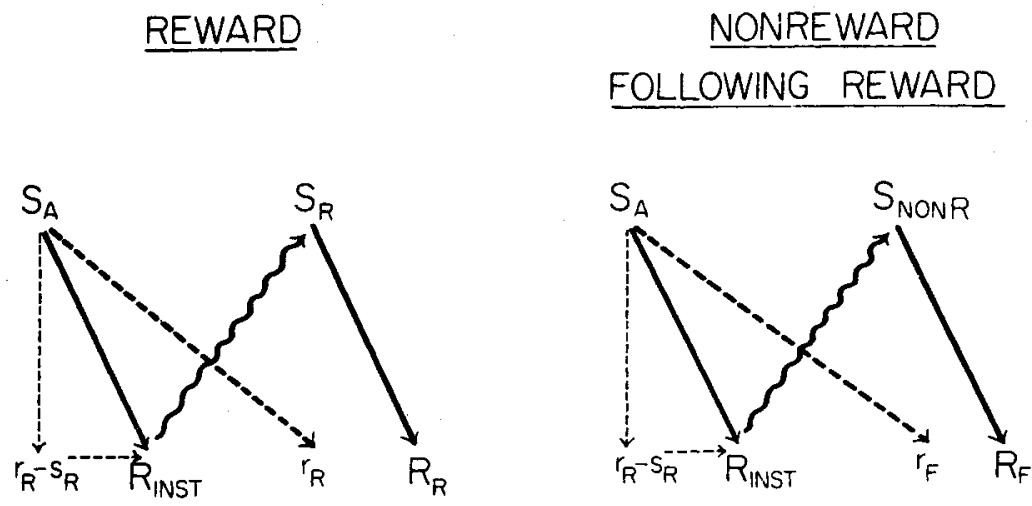

Figure 1. Schematic representation of (left) the conditioning of anticipatory reward $\left(r_{R}\right)$, and (right) the manner in which $r_{R}$ and its feedback stimulus $\left(s_{R}\right)$ in the absence of reward $\left(S_{n o n R}\right)$ combine in the evocation of primary frustration $\left(R_{F}\right)$ and in the subsequent conditioning of the response of anticipatory frustration and its feedback stimulation $\left(r_{F}-s_{F}\right)$. See text for further details. From "Frustration and Persistence: Resistance to Discrimination Following Prior Experience With the Discriminanda," by A. Amsel and J. S. Ward, 1965, Psychological Monographs, 79 (4, Whole No. 597), p. 2. Copyright 1965 by the American Psychological Association. Adapted by permission. 
sient, nonassociative, motivational (energizing) effect on responses with which it coincides. That is to say, the immediate consequence of $R_{F}$ is a short-term increment in generalized, energizing drive or arousal. The second property of frustration is the primary frustration drive stimulus $\left(\mathrm{S}_{\mathrm{F}}\right)$, a feedback stimulus from $\mathrm{R}_{\mathrm{F}}$ which acts, like any other stimulus, to cue, guide, and direct behavior; that is, it acts associatively (e.g., Amsel \& Ward, 1954). It is important to note that this hypothetical stimulus $\left(\mathrm{S}_{\mathrm{F}}\right)$ is not the result of learning, as are, for example, $s_{R}$ and $s_{F}$, the feedback stimuli from conditioned reward $\left(r_{R}\right)$ and conditioned frustration $\left(r_{F}\right)$, the third and fourth properties of frustration, and the ones that bear perhaps the heaviest theoretical burdens. The latter factors refer to the manner in which frustration influences responses that precede the frustrating event, and here the theory relies on logic derived from its Pavlovian antecedents: With repeated occurrences, conditioned stimuli (CSs) paired with primary frustration come to evoke a classically conditioned form of $R_{F}$, designated $r_{F}$. As with $r_{R}$, of which it is the aversive counterpart, $r_{F}$ is initially evoked, in an instrumental sequence, by stimuli in the region of the goal event and later in the region of instrumental response, and is assumed to increase in strength as a function of nonrewarded trials, reaching an asymptotic strength appropriate to the strength of $R_{F}$. There follows in the book an extended review of experiments that provide support for these four conceptualized properties of frustration.

\section{THE EXPLANATORY DOMAIN OF FRUSTRATION THEORY: AN OVERVIEW}

After establishing the energizing, directive, and suppressive properties of primary and conditioned frustration, the book goes on to examine their explanatory possibilities. The earliest, most fundamental of these is a set of hypotheses, reviewed briefly earlier, that concerns the influence of $r_{F}-s_{F}$ on appetitive instrumental responding that continues to be performed in its presence, and a parallel set of hypotheses (covered in chapter 5 of the book) that describes the role of primary and conditioned frustration in successive discrimination learning. The wellknown finding, in the first case, referred to as the PREE, is that the rate of experimental extinction of a response is slower following PRF than following CRF training: animals (and humans) are more persistent-resistent to extinction-after exposure to a PRF than to a CRF schedule. The left-hand side of Figure 2 outlines the familiar four-stage hypothesis of the PREE, a sequence leading

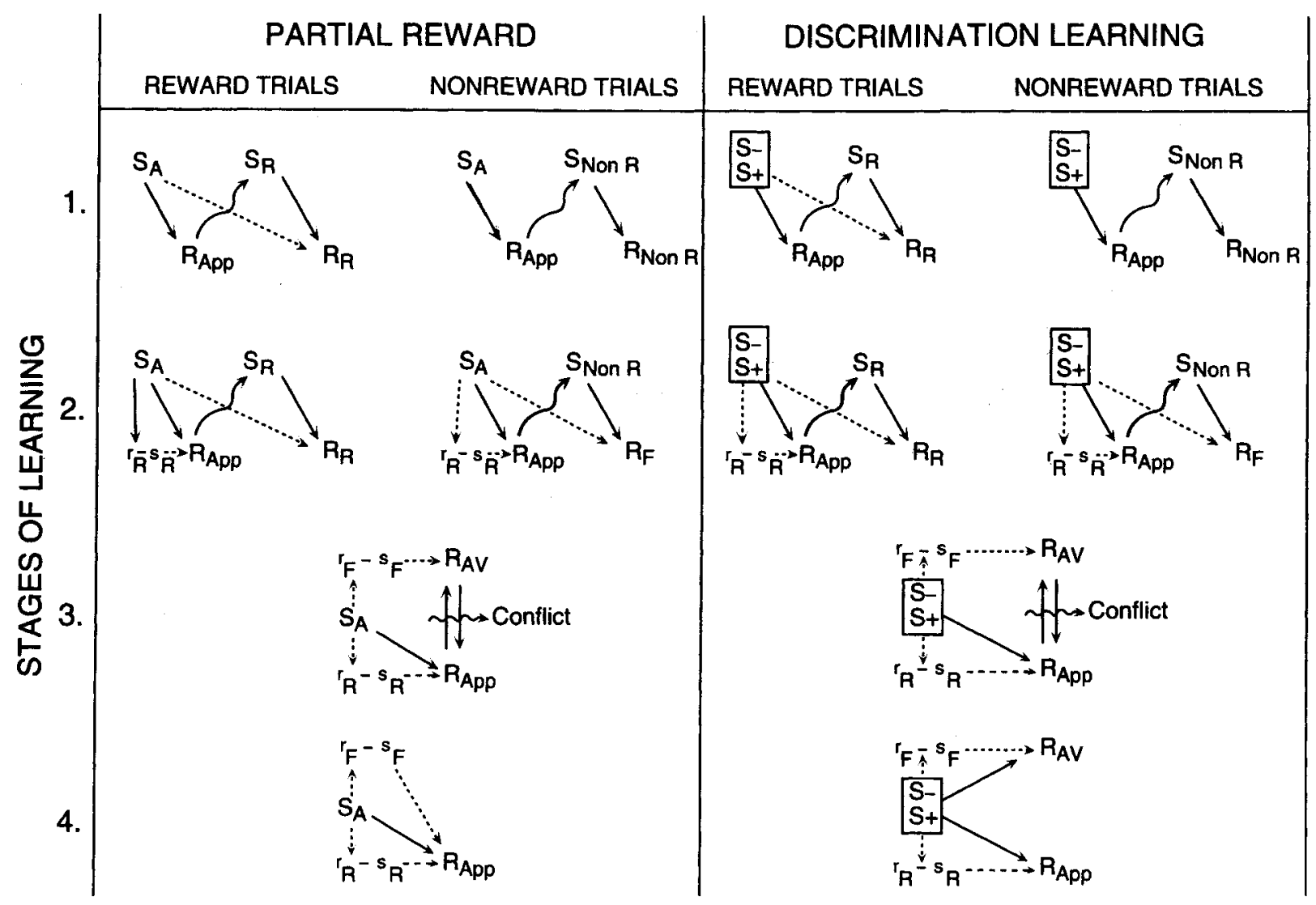

Figure 2. Diagrammed sequence of hypotheses relating frustrative nonreward to stages of partial reward and discrimination learning. From “The Role of Frustrative Nonreward in Noncontinuous Reward Situations," by A. Amsel, 1958, Psychological Bulletin, 55, p. 109. Copyright 1958 by the American Psychological Association. Adapted by permission. 
to the development of relative persistence. Stage 1: The occurrence of rewards in early PRF training results in the conditioning of $r_{R}$ to the stimuli $\left(S_{A}\right)$ of the situation. Stage 2: Once $r_{R}$ is sufficiently strong and its feedback stimulus, $s_{R}$, elicits approach, nonrewards evoke primary frustration $\left(R_{F}\right)$, and $R_{F}$ becomes the unconditioned stimulus (UCS) for the conditioning of $r_{F}$ to $S_{A}$, the cues present on both rewarded $(\mathrm{R})$ and nonrewarded $(\mathrm{N})$ trials. Stage 3: As $r_{F}$ becomes stronger, its feedback stimulation $\left(\mathrm{s}_{\mathrm{F}}\right)$ evokes responses that compete with the established instrumental response and the mean amplitude of that response decreases, mainly because of increased conflict and the consequent response variability. Stage 4: As the subject continues to perform the response to the goal, $\mathrm{s}_{\mathrm{F}}$ comes to evoke the instrumental response because of its repeated elicitation and inconsistent reinforcement in the presence of $s_{F}$ (dashed line, Stage 4). The mechanism invoked is instrumental counterconditioning-the conditioning approach to $\mathrm{s}_{\mathrm{F}}$. Other possible outcomes of PRF training, however, are (1) that the animal will remain in conflict (in Stage 3), or (2) that the conflict of Stage 3 will be resolved by the counterconditioning of avoidance to $s_{R}$ (not shown in Figure 2). The result of the PRF training in the latter case will be desistance (faster extinction) instead of persistence. The right-hand side of Figure 2 adapts these explanatory concepts to successive discrimination learning, the first three stages being identical to those in the PREE, the fourth being the split-off of approach to $\mathrm{s}_{\mathrm{R}}$ and avoidance to $\mathrm{S}_{\mathrm{F}}$ as the associative properties of the two discriminanda become differentiated.

To reiterate, in 1951-1952, the explanatory scope of the theory included the frustration effect and the negative incentive-contrast effect of Elliott (1928) and Crespi (1942). In 1958, the PREE and simple discrimination learning were added. In 1962, the theory was shown to incorporate and to account for a number of other phenomena, including the early appearance and later disappearance of primary frustration in discrimination learning, and the effects of prediscrimination exposure to various schedules of $\mathrm{R}$ and $\mathrm{N}$ on subsequent discrimination learning: facilitation of and resistance to discrimination (chapter 5). The theory has also addressed the long-time retention and durability of persistence in the face of experiences interpolated between acquisition and extinction (chapter 4), more recent developmental considerations of these phenomena (chapter 7), and considerations of their neurobiological substrate (chapter 8). Some other areas in which investigators have applied explanations in terms of frustration theory are the overlearning-extinction effect; the overlearning-reversal effect in discrimination learning; the phenomenon of subzero extinction (a finding analogous to the depression effect); the paradoxical Haggard-Goodrich partial reinforcement acquisition effect (PRAE), in which partially rewarded animals show higher speeds in acquisition than continuously rewarded animals show; the action of certain drugs like alcohol and sodium amytal to attenuate the PRAE and the PREE; certain other phe- nomena of contrast, including simultaneous negative contrast and aspects of operant behavioral contrast; the appearance of certain "adjunctive" behaviors, like schedule-induced polydipsia and aggressive behaviors in Skinnerian operant experiments; the role of the limbic system in the FE, the PREE, and certain other phenomena of reinforcement; phenomena of transfer of persistence across situations and motivational-reinforcement conditions, including the effects of prior experience on later behavior, and the operation of discontinuously negative reinforcement (Logan, 1960) in "regression" to earlier "successful" ritualized forms of behavior. (These and other phenomena, predicted and explained by frustration theory, with specific citations of some of the earliest relevant experimental work, are contained in an appendix at the end of the book.)

An extension of the theory, a more general account of persistence, views the consequences of partial reinforcement as a special case of a more general rule (Amsel, 1972a). The more general theory, and some of the experimental work related to it, also presented in some detail in chapter 4 , begins with a treatment of behavioral habituation as a case of generalized counterconditioning. A postulate of this theory is that counterconditioning is the mechanism for behavioral habituation and that habituation is an active rather than a passive process. As a consequence, an instrumental response performed in the presence of disruptive stimulation will be a persistent response, relatively resistant to the effects of these (and other) disruptive stimuli. As we shall see, this theoretical extension is useful in explanations of transfer of persistence effects, and of the work on fear-frustration commonality (Wagner, 1966). The extreme form of this commonality, in Gray's (1967) terms, is that "fear equals frustration," an idea with which I do not agree or find useful. The position that I adopt in this book is that fear and frustration do have in common the capacity to disrupt behavior and to contribute to the learned persistence. However, one of the theoretical advantages of this more general position is that it encourages a more developmental perspective (chapter 7), which, in turn, moves the work on persistence and dispositional learning in general in the direction of relating the developing behavioral effects to the developing brain (chapter 8).

The remainder of this précis deals, in somewhat more detail, with these last two items: the generality and transfer of persistence, and some recent developmental and neurobiological directions in the study of dispositional learning and memory.

\section{PERSISTENCE: THE MORE GENERAL CASE}

The term persistence refers to a tendency for organisms to pursue goal-directed activities despite frustrative nonrewards, punishments, obstacles, or deterrents - in general, in the face of negative consequences of any kind. Persistence takes forms other than the appetitive PREE. Among these are continued approach in the face of pun- 
ishment (Banks, 1966; Fallon, 1968; Holt \& Gray, 1983; Linden \& Hallgren, 1973; Martin, 1963; Wagner, 1969), which has been called "courage" (Miller, 1960); a form of "regression" in which anticipatory frustration is the prime mechanism (Rashotte \& Amsel, 1968; Ross, 1964); and retardation of discrimination (Amsel, 1962), which we have called "resistance to discrimination" (Amsel \& Ward, 1965), and which will not be treated in detail in this précis. I have argued that, to the extent that these have been investigated, the evidence is that the mechanisms operating in all of these cases of persistence are similar to those in resistance to appetitive extinction: For persistence to develop there must be some uncertainty of outcome; there must be significant probabilities both that reward will be present and that it will be absent following a response, or, more generally, that a response will be followed by both positive and negative consequences. (Several alternative conceptualizations of the mechanisms that mediate persistence [Capaldi, 1967; Lawrence \& Festinger, 1962; Sutherland, 1966, to mention three of the more influential ones], each of which has been applied in its own special theoretical and experimental context, are presented in some detail in chapter 6 of the book.)

The circumstance under which frustration, fear, or disruptive events in general lead to persistence is that there must be intermittent reward and nonreward (or intermittent reward and punishment) for the same behavior in approximately the same situation. And it is of course possible, on the basis of a principle of fearfrustration commonality (Brown \& Wagner, 1964), that early but inconsistent frustration will result in later persistence in the face of punishment and vice versa. These and other specific instances of transfer of persistence have important implications for the developmental study of emotion, temperament, and personality-which is to say, for the end points of dispositional learning and memory.

A feature of this book is the experimental support that it provides for the generality of persistence and the transfer of the products of dispositional learning from one situation to another. (In chapter 4, for example, experiments are presented that involve reward-schedule comparisons within the individual subject, and in chapter 5 the same considerations are applied to the facilitation and retardation of discrimination learning by prediscrimination experiences.) These experiments have shown that there is situational transfer of suppression and persistence based on frustration. The procedure in these within-subjects experiments is, for example, to continuously reinforce an approach response every time it is made in the presence of one stimulus (e.g., the black, CRF alley), and to partially reinforce the same response when it is made in the white, PRF alley. The finding in these experiments is that, when the response is extinguished in both alleys, the PREE pattern emerges in both alleys when compared with a control condition in which continuous reinforcement is given in both alleys (e.g., Amsel, Rashotte, \& Mackinnon, 1966; Brown \& Logan,
1965). These simple transfer-of-persistence experiments permit the interpretation that, in extinction, there is a degree of interoceptive control by the feedback cues from conditioned frustration $\left(\mathrm{s}_{\mathrm{F}}\right)$, and that this internal control overrides the external stimulus control of the differential, black and white alley colors. The explanation I favor for this generalized PREE, to use Brown and Logan's term, is mediated generalization of the counterconditioned $\mathrm{s}_{\mathrm{F}} \rightarrow$ approach association from the PRF alley to the CRF alley. To put it in descriptive terms, as soon in extinction as anticipatory frustration occurs in the white PRF alley, the persistence mechanism generalizes to and "switches on" in the black CRF alley: The addition of $s_{\mathrm{F}}$ to the stimulus complex of the black alley brings with it a rearrangement of the habit-family hierrarchy in that black alley, and the response of approaching in the presence of $\mathrm{s}_{\mathrm{F}}$ in the white alley overrides the response of avoidance in the presence of $\mathrm{s}_{\mathrm{F}}$, elicited by the relatively less controlling (black) external cues.

In chapter 7, this thinking is applied to the development of persistence. Here, a more relevant and realistic within-subjects experiment is one in which the CRF and PRF training occur not only in different stimulus contexts, but also in successive phases (at separate ages), rather than being mixed together in a single time-phase, as in the earlier within-subjects experiments. In the separatephase paradigm, the experimental within-subjects sequence is, for example, $\mathrm{PRF} \rightarrow \mathrm{CRF} \rightarrow \mathrm{EXT}$ and the control sequence is $\mathrm{CRF} \rightarrow \mathrm{CRF} \rightarrow \mathrm{EXT}$, and we look in the terminal extinction phase for the effects of earlier PRF (as compared with CRF) training conducted under different stimulus conditions. The question is this: Can the effects of prior-even very early-experiences with intermixed rewards and frustrations in one situation transfer to the extinction of a continuously rewarded behavior learned later in a different situation? The answer, as we shall see, is that they can.

\section{Regression as a Transfer of Persistence Phenomenon}

A number of early studies deal experimentally with the relationship of frustrative extinction to the variability and aggressiveness of behavior (Barker et al., 1941; Miller \& Miles, 1935, 1936; Miller \& Stevenson, 1936). Frustration theory incorporates these early results; the theory has also predicted experimental results that appear to show a relationship between frustration, both unlearned and learned, and regression-the return to an earlier "successful" mode of behavior.

Chapter 4 outlines the sense in which a frustrationregression hypothesis is tenable. We begin with the counterconditioning view of persistence, which implies that a connection of some kind is formed in acquisition between an initially disruptive, emotional, mediating event and some ongoing behavior. We have shown that if this mediational control is powerful, $\mathrm{s}_{\mathrm{F}}$ will elicit approach not only in the situation in which the counterconditioned connection was originally formed, as, for example, in the PRF condition, but also in other situa- 
tions in which anticipated frustration comes into play; that is to say, mediated transfer-of-persistence occurs.

Still, how do we get from transfer of persistence and the mechanism of mediated generalization to regression? An early experiment demonstrated that, even if training is conducted at a 3-day intertrial interval, persistence acquired under PRF conditions can survive a long "vacation" followed by a block of CRF trials (that should "wipe out" the persistence) to increase resistance to subsequent extinction (Rashotte \& Surridge, 1969). It is also the case that persistence acquired in one situation can have effects in a different situation, involving different responses and different motivational-reward conditions (e.g., Ross, 1964), which is to say that there can be regression to a mode of persistent behavior learned earlier in the context of PRF acquisition, and this regression can be said to be mediated by anticipated frustration. In this case, to persist is to regress. A frustrationregression hypothesis is therefore supported if what we mean by frustration is the response-evoking properties of feedback cues $\left(\mathrm{s}_{\mathrm{F}}\right)$ from anticipatory (conditioned) frustration $\left(r_{F}\right)$; a frustration-aggression hypothesis refers to the effects of primary (unconditioned) frustration $\left(R_{F}\right)$ and its feedback cues $\left(S_{F}\right)$. The difference, then, is in the nature of the response-evoking stimulation, emerging in the former case out of the "anticipation" of frustration, and in the latter case out of its "direct experience."

\section{Transfer of Persistence: How General?}

Two questions posed by a general theory of persistence can be separated: (1) Is instrumental counterconditioning of ongoing approach behavior to disruptive stimulation in general involved as a mechanism in the dispositional learning of persistence? (2) Is there transfer from one persistence system to another? In other words, is there a disposition to persist, a general "pool" or "trait" of persistence? Trying to answer the first question necessarily gets us involved in the second, although to say that a single kind of mechanism may be involved in most or all instances of learned persistence does not require that persistence involve a single, unitary system: It does not require that persistence acquired in any set of disruptive circumstances necessarily transfer to any other. (We have already seen evidence for this kind of transfer in the case of disruption by frustration.) By the same token, demonstrating transfer of persistence from one set of conditions to another does not mean, necessarily, that the mechanism of persistence is the same in both systems, although our view of this aspect of life would be simpler if this generality did in fact hold. In the final part of this section, we will consider, briefly, an outline of some of the experimental evidence that would be helpful in answering the questions about generalized persistence and transfer of persistence across situations, motivational conditions, response systems, and disruptive mechanisms. The following eight categories of experiments summarize the evidence to date.
1. The most obvious, the simplest, and certainly the category most frequently studied in experiments is the one in which the persistence is learned under one or other of a number of reward-schedule conditions: PRF, variable magnitude of reward (VMR), partial delay of reward (PDR), or other variations of goal events, and transfer of the learned disposition is to extinction of responding in the same situation. In these cases, the persistence is acquired and tested in the same appetitive motivational-reward conditions and derives from the PRF, VMR, or PDR (or even the discontinuously negatively correlated, or DNC) condition, even though, in some of these experiments (e.g., Donin, Surridge, \& Amsel, 1967; Rashotte \& Amsel, 1968; Rashotte \& Surridge, 1969; Ross, 1964), the test for survival of persistence follows a CRF phase that is interpolated between acquisition and extinction.

2 . Another case of transfer of persistence is across different appetitive conditions: from hunger to thirst, as in the Ross (1964) experiment (see also Mellgren, Hoffman, Nation, Williams, \& Wrather, 1979). Here, although the disruptive effect occurs in PRF training under hunger in Phase 1, the survival and transfer is through CRF under thirst in Phase 2 to extinction under thirst in Phase 3. Still, the transfer of persistence in this case, as in Case 1, involves the general properties of anticipatory frustration as the disruptor of behavior.

3 . In a third case, the transfer of persistence from acquisition to extinction is still across appetitive conditions; however, the disruptive factor is not related to nonreward (or reduced or delayed reward or blocking of reward) but to the introduction of disruptive agents that are external to the reward itself (Banks, 1967; Brown \& Wagner, 1964; Fallon, 1971; Miller, 1960; Ratliff \& Clayton, 1969). There is in these experiments transfer of persistence across the goal events of frustration and punishment. This same kind of transfer effect can be shown when the disruptive event in acquisition is a loud tone, rather than anticipatory frustration or shock (Amsel, Glazer, Lakey, McCuller, \& Wong, 1973).

4. The fourth case is a version of the third. Like experiments on "US devaluation" (e.g., Holland \& Rescorla, 1975), it involves adulterating or otherwise decreasing the attractiveness of reward for one group and not for another. An example is transfer of persistence learned in approach to an anticipated aversive taste and tested in approach to anticipated frustration. In this experiment (Chen \& Amsel, 1980b), the rat is "immunized" against the avoidance of a taste, made aversive with lithium chloride ( $\mathrm{LiCl})$, by giving it prior, independent runway training in which reward involving that taste is given inconsistently-on a PRF schedule. The point is that a learned taste aversion, formed when taste and LiCl-induced illness are paired in a Pavlovian arrangement, can be reduced by first rewarding an instrumental response with that taste on a PRF schedule.

5. In this kind of experiment, transfer of persistence is investigated across different definitions of reward 
schedules and different response topographies (McCuller, Wong, \& Amsel, 1976). The transfer in the case was from operant training on successive fixed ratios (FR) to extinction in a runway at one trial a day. Resistance to extinction in the runway was systematically and positively related to terminal ratio requirements of the previous operant barpress training. A follow-up experiment (Wong \& Amsel, 1976) tested the animals from McCuller et al. after they had been given a 2-month vacation. The rats were then given 8 days of FR-10 barpress training, followed by 9 days of FR-10 barpress extinction. Then, in the last phase (fifth phase of both experiments taken together), all rats received 12 rewarded trials in a runway with a 300-mg-pellet reward, followed by $32 \mathrm{ex}-$ tinction trials, all at 1 trial a day. In the final runway extinction, differential persistence resulting from the original differential FR of responses to reinforcement was still present. Another example in this category involves only reinforced behaviors. After barpressing for food on a variable-interval schedule, rats earned food in a runway for varying degrees of effort and then barpressed again for food. Barpressing in the third stage was directly related to the amount of effort required in the second (Eisenberger, Terborg, \& Carlson, 1979).

6 . There is a series of experiments in which transfer of persistence is over different situations and different "appetitive" conditions, but not hunger and thirst as in Case 2. The transfer in one such experiment was from disruption of imprinting by electric shock to disruption of food approach by anticipatory frustration. The imprinting was to a flickering light and a pulsating tone. The subjects were domestic chicks. Following imprinting, imprinting-shock, and control treatments, persistence was tested under normal nonreward-extinction conditions following both CRF and PRF training to approach food in a runway. There was some evidence that the imprinting procedure by itself increased persistence in extinction following CRF acquisition; however, the main effect was in the imprinting-shock condition, which increased resistance to extinction following both CRF and PRF appetitive acquisition (Amsel, Wong, \& Scull, 1971).

7. This is an apparent case of transmotivational training which results in persistent approach to an aversive event without concurrent appetitive reinforcement. The first application of this technique was called "coercedapproach" training (Wong, 1971a, 1971b). The question is this: Can you train an animal to persist in approaching, even though its approach gets it nothing but aversive stimulation? And, if you can, will the persistence acquired in this manner transfer to the extinction of an appetitively motivated response? Wong demonstrated in these experiments that, by whatever method the rats were trained to consistently approach an area in which they received a shock, these animals were subsequently more resistant to extinction following training involving food reward. In another series of experiments (Nation, Rather, Mellgren, \& Spivey, 1980), rats were given PRF or CRF training in a straight alley in either a shockescape or an appetitive paradigm, after which they re- ceived CRF training under motivational conditions opposite to those in the first phase. In a third phase, responses were extinguished according to the motivational conditions experienced in the second phase. The results were (1) that PRF training in the first phase increased resistance to extinction in the third, (2) that this transmotivational PREE survived interpolated experiences with extinction, a 1-week "vacation," and CRF reacquisition, and (3) that when aversive nonreinforcement (failure to reinforce an escape response with shock reduction) was in some cases followed by appetitive reinforcement, and appetitive nonreinforcement was in some cases followed by shock-escape reinforcement, both these nonreinforcement-reinforcement combinations resulted in increased persistence.

8. The final case involves three experiments with demonstrations of transferred effects from ordinary habituation training to appetitive resistance to extinction and vice versa. This is different from the others in that the "disruptive" stimulation is not introduced in the context of appetitive learning or even, as in case 7 , in relation to the same instrumental response. It is introduced in the separate context of a simple habituation procedure (Chen \& Amsel, 1977). In the first experiment, a number of unsignaled shocks were given in Phase 1 "off the baseline." Phase 2 was appetitive runway acquisition, under either CRF or PRF conditions, and Phase 3 was extinction followed in the same runway. In the second experiment, the shock treatment came in Phase 2 between CRF or PRF acquisition in Phase 1 and extinction in Phase 3. In the third experiment, shocks in Phase 2 intervened between appetitive CRF acquisition in Phase 1 and extinction involving shock as well as nonreward in Phase 3. The shock durations in these experiments were increased in 1-sec increments per day from $1 \mathrm{sec}$ on Day 1 to $5 \mathrm{sec}$ on Days 5 and 6 . The main finding was that, compared with unshocked controls, shock facilitated acquisition in Experiment 1 and led to increased resistance to extinction and/or punishment in all experiments.

The work described in this section is heavily weighted on the concept of persistence; we have seen, however, that the explanatory scope of the theory extends well beyond the empirical particulars that can be organized under this heading. Nevertheless, the study of the acquisition of learned persistence, based on frustration or in its more generalized form, and the body of evidence suggesting that it can survive a variety of conditions that might be thought to reduce or eliminate it has been influential in the move toward more developmental and psychobiological approaches to the study of dispositional learning and memory, and these are examined in chapters 7 and 8 . The exciting possibility is that, with these approaches, we might uncover the roots in early learning of general dispositions or characteristics of temperament, perhaps at sensitive stages of development. This précis concludes with a brief examination of the developmental and psychobiological work that is summarized in chapters 7 and 8 of the book. 


\section{DEVELOPMENTAL AND NEUROBIOLOGICAL APPROACHES}

The introduction to chapter 7 of Frustration Theory returns to a family of distinctions introduced at the beginning of the book (Table 1 of this précis), this time in the context of a discussion of levels of function. The point is made that these distinctions, most of which have been around for some time, reflect these different levels. In Squire's (1987) terms, they are important in the study of the neuropsychology of human memory; in ours, in the developmental study of learning and memory in an animal model. All these basic distinctions appear, in one sense or another, to involve at least two functional levels, which go by a variety of names: implicit versus explicit; noncognitive versus cognitive; $S-R$ versus cognitive; procedural versus declarative; procedural versus propositional (semantic and episodic); habit systems versus memory systems, and, in the present case, dispositional versus representational. Other much earlier distinctions representing differential levels of function are to the same effect: Schneirla's (1959) approach withdrawal versus seeking avoidance; Bitterman's (1960), carry-over versus reinstatement; and our simple classical versus Pavlovian versus instrumental conditioning in one version (Amsel, 1972b), and nonparadoxical versus paradoxical in another (Amsel, 1986; Amsel \& Stanton, 1980).

In recent years, we have examined the ontogeny of a number of familiar reward-schedule effects, which carries out Step 3 of the strategy, outlined early in this book (see Table 1), with respect to their presence or absence and their order of first appearance at certain stages of development. This examination strengthens the proposition that there are two systems of learning and memoryone more "primitive" than the other. The first is the implicit stamping-in action of reinforcers, which can be said to predominate in lower phyletic or ontogenetic forms; the second, more explicit, system is perhaps present in all mammals but, arguably, not very early in life in relatively altricial ones (e.g., the infant rat, and perhaps even the human infant). The latter explicit system involves expectancies - conditioned forms of primary reward, frustration, punishment, and relief--an important aspect of the "mind" to which Hebb (1980) alluded in his own discussion of levels of function, and which he linked to motivational and emotional development.

At the beginning of this précis, in the context of our interest in dispositional learning, I have provided a table showing the order of first appearance of a number of reward-schedule effects in Sprague-Dawley rats of the Holtzman strain (see Table 2). The order of appearance of these effects-PA before PREE before PDREE before SNC and so on - can be taken to represent maturing levels of dispositional functioning in appetitive learning. Some of these effects, such as the last three listed above, can be said to be "paradoxical" in two senses: The first sense is of a kind of reversal of expectation. Here are some examples: the smaller the percentage of reward in acquisition, and the longer the delay of reward in acqui- sition, and the more variable the magnitude of reward in acquisition, the greater the resistance to extinction (PREE, PDREE, VMREE, respectively); the greater the magnitude of reward in acquisition, the smaller the resistance to extinction (the MREE); and the greater the magnitude of reward early in acquisition, the lower the level of performance when small reward follows large reward (SNC). These behavioral effects all represent acquired dispositions, and they depend in one way or another on detection of and reaction to discrepancy, which in turn involves conditioned incentive factors.

These effects are also paradoxical in a second, more formal-theoretical sense: They are not predicted or explained by-indeed, they go against-all classical and most modern theories of learning and memory: the theories of Thorndike, Guthrie, Tolman, and Hull; the mathematical models of Bush and Mosteller (1951), Estes (1950), and Rescorla and Wagner (1972); and many, if not all, of the newer cognitive interpretations. Years ago, Capaldi's $(1966,1967)$ sequential theory and my own theory (Amsel, 1958, 1962, 1967) addressed some of these paradoxical effects. So have the more recent model (DMOD) of Daly and Daly (1982) and a still more recent application of DMOD to our developmental results (Daly, 1991), both of which combine the RescorlaWagner mathematical form with assumptions taken from frustration theory.

A thesis that is central to the latter parts of this book (and earlier, Amsel, 1986; Amsel \& Stanton, 1980) is that the transition from nonparadoxical to paradoxical functioning represents a fundamental developmental sequence, as do transitions from lower to higher paradoxical levels. This is in line with a more recent statement by Squire $(1987$, p. 168$)$ that "in ontogeny declarative memory develops later than procedural memory," a view previously expressed in other terms in the writings of others (Bachevalier \& Mishkin, 1984; Mandler, 1984; Nadel \& Zola-Morgan, 1984; Schacter \& Moscovitch, 1984).

In chapters 7 and 8 of the book, I present results from (1) ontogenetic investigations in the rat, (2) cross-species comparisons in adult fishes, turtles, pigeons, and rats (see reviews by Bitterman, 1965, 1975), and (3) psychobiological investigations involving brain lesions, pharmacological manipulations, electrophysiological stimulation and recording, and developmental neurobiology. These results are taken to support the thesis that transitions in levels of functioning, exemplified by these reward-schedule effects, contribute to our understanding of dispositional learning and memory in emotionaltemperamental development, and to our understanding of the factors that facilitate and retard it. These dispositional phenomena are known to be influenced in the adult rat by drugs that affect, lesions that destroy, and other treatments that compromise portions of or systems in the hippocampal formation of the brain. These interventions appear to exert at least part of their action through reduction of primary and conditioned frustration and their behavioral consequences. 
Chapter 8 begins with the background and rationale for a developmental psychobiology of dispositional memory based on the experimental work summarized in chapter 7, and on the extensive available literature on the neurobiology of hippocampal function; it ends with a description of some work, now very much still in progress, that can be regarded as a possible behavioral assay of the effects on working memory and persistence in infant and adult rats of intrahippocampal interventions such as lesions, intrauterine and/or postnatal effects of ethanol, and focal $\mathrm{x}$-irradiation.

The basic rationale for this research, as proposed in the book, can be summarized as follows: With respect to dispositional learning and memory, the infant rat is like the hippocampally damaged adult. The argument and evidence for this position is encapsulated in a quotation from Angevine and Cotman, who, in their Principles of Neuroanatomy (1981), write: "the hippocampus holds the secret to limbic system functions, or at least a large part of it... Lesions of the hippocampus in experimental animals make it more difficult for those animals to change an ingrained response to a new one" (p. 261). The importance of this position and of our hypothesis in relation to our developmental work rests in the fact that, in the rat, a significant part of hippocampal cell neurogenesis, neuronal elaboration, and circuitry is postnatal. This offers the investigator a natural animal model not only for gradually increasing levels of hippocampal structure, but also function, paralleling the developing paradoxical effects (Amsel, 1986; Amsel \& Stanton, 1980). It can be said that hippocampal insult in the adult rat, like hippocampal immaturity in the infant, reduces the level of functioning from "paradoxical" to "nonparadoxical"; in Schneirla's (1959) terms, from the level of function that he described as "seeking and avoidance" to the level that he characterized as "approach and withdrawal." The effect of hippocampal damage on learning and memory in the adult, or even in the older infant rat, is analogous but opposite to the familiar recovery of function; it is a kind of reversion of function.

In the book, I review the evidence that relates the integrity of the hippocampal formation in the adult rat to some of the reward-schedule effects. (There was, to my knowledge, no work before ours on these behavioral effects over the infant-to-postweanling age range, and no hypotheses relating these phenomena to the developing neural substrate at these ages.) The work described at the end of chapter 8 must be regarded as the leading edge of a much larger body of research designed to answer questions such as these: Is a level of function in dispositional learning and memory that is thought to depend on hippocampal maturity in the intact adult degraded (or is it spared) when that area of the brain suffers damage or neuronal agenesis in infancy that presumably prevents its normal development? Is there, even in the developing infant rat-say, at preweanling age - delay of reversion of function as a result of such hippocampal interventions? And if these functions are degraded in infant-to-preweanling animals, is there significant recovery of function in adulthood?

To summarize, the working hypothesis developed in chapters 7 and 8 is that the infant rat is like the hippocampally damaged adult, and, beginning with a brief review of hippocampal morphology, previously available evidence is adduced to support this hypothesis. This is followed by a brief overview in the adult rat of the work on the effects on dispositional learning of lesions, $\mathrm{x}$-irradiation, alcohol, and drugs; on the relation of hippocampal EEG (theta) to learned persistence; and on hippocampal sensory evoked potentials during discrimination learning. There follows an extensive discussion of the behavioral inhibition system (BIS), a circuit proposed by Gray, following the early accounts of Douglas, Simonov, Vinagradova, and others, to account for the mechanisms of inhibition and persistence, the central factors in frustration theory. Behavioral tests of the effects of interventions in the BIS, in the form of subicular, hippocampal, and septal lesions, are described, and the strengths and weaknesses of this theory are noted. The last part of the chapter, based on the ontogeny of the reward-schedule effects described in chapter 7 , is a body of experimental results that emerge from the proposition that the relation between dispositional learning and memory and the brain can best be understood in two interlocking ways. One is to study the relationships that exist between the developing behavioral effects and the intact developing brain; the other is to interfere with features of that brain development, particularly those that are implicated in dispositional learning in the adult rat, and look for predicted retardations in the development of those behavioral effects. The chapter closes with a review of a small body of experimental work now available in these regards - on infant lesions, prenatal and postnatal exposure to ethanol, and postnatal exposure to $\mathrm{x}$-irradiation as they affect PA and the PREE in infant, weanling, and adult rats.

\section{REPRISE: REVISITING THE STRATEGIC OUTLINE}

Chapters 3-8 of Frustration Theory represent an attempt to follow a sequence of six logical guiding statements or strategic steps outlined in Table 3 of this précis. Chapter 9 is a reprise of the contents of these chapters that examines the manner and extent to which the themes of Table 3 have been developed in the book. The conclusion at which I arrive following this examination is that the book follows these six guiding steps reasonably well, with some interesting and unexpected implications for frustration theory. These are expressed as a set of six hypothetical statements, reproduced in full below, and they represent a possible extension, if not revision, of the four original premises of frustration theory.

1. Persistence in infants and adults very likely depends on two quite different mechanisms and neural substrates.

2. In the normal infant rat, there is innate persistence related to immaturity of the BIS, and CRF training at 
about 2 weeks of age results in a reduction in persistence, whereas at this age PRF training begins to permit a relative conservation of persistence. (The immature substrate may also be in control of the very remarkable early evidence of single patterned alternation (PA) at short intertrial intervals, another example of the operation of Schneirla's approach-withdrawal function.)

3. In adults, PRF training appears to return the rat to an earlier ontogenetic level by somehow overriding mature hippocampal function, the suppressive action of the mature BIS.

4. The mature function, which permits detection of discrepancy (Gray, 1982; Simonov, 1974; Vinogradova, 1975), also promotes rapid extinction following CRF training and is involved in the expectancy-based suppressive effects on nonrewarded trials in the more adult ("seeking and avoidance") mode of memory-based (PA) learning.

5 . One way to reduce, or even negate, mature hippocampal function consists in damage to the hippocampal formation, broadly defined to include, in addition to the hippocampus proper, the dentate gyrus, the septum and its cholinergic afferents and efferents, the subiculum, and the entorhinal cortex. Another way consists of PRF training - either PRF training preceding extinction or PA learning.

6. In adults, maximal persistence in a particular context (or even persistence more generally) and optimal memory-based learning at the longer intertrial intervals depend on an intact hippocampal formation, and, in Gray's terms, a functioning BIS suppresses behavior but can be overridden by a history of PRF experience in that particular context.

These six statements are, of course, highly provisional modifications of the theory and are best regarded as working hypotheses for further research.

\section{REFERENCES}

AMSEL, A. (1951). A three-factor theory of inhibition: An addition to Hull's two-factor theory. Paper delivered at the meeting of the Southern Society for Philosophy and Psychology, Roanoke, VA.

AMSEL, A. (1958). The role of frustrative nonreward in noncontinuous reward situations. Psychological Bulletin, 55, 102-119.

AMSEL, A. (1961). Hope comes to learning theory. Review of O. H. Mowrer's Learning theory and behavior. Contemporary Psychology, 6, 33-36.

AMSEL, A. (1962). Frustrative nonreward in partial reinforcement and discrimination learning: Some recent history and a theoretical extension. Psychological Review, 69, 306-328.

AMSEL, A. (1967). Partial reinforcement effects on vigor and persistence: Advances in frustration theory derived from a variety of within-subjects experiments. In K. W. Spence \& J. T. Spence (Eds.), The psychology of learning and motivation: Advances in research and theory (Vol. 1, pp. 1-65). New York: Academic Press.

AMSEL, A. (1972a). Behavioral habituation, counterconditioning, and a general theory of persistence. In A. H. Black \& W. F. Prokasy (Eds.), Classical conditioning II: Current research and theory (pp. 409-426). New York: Appleton-Century-Crofts.

AmSEL, A. (1972b). Inhibition and mediation in classical, Pavlovian and instrumental conditioning. In R. Boakes \& S. Halliday (Eds.), Inhibition and learning (pp. 275-299). London: Academic Press. AMsEL, A. (1986). Developmental psychobiology and behaviour the- ory: Reciprocating influences (Daniel E. Berlyne Memorial Lecture). Canadian Journal of Psychology, 40, 311-342.

AMSEL, A. (1989). Behaviorism, neobehaviorism, and cognitivism in learning theory: Historical and contemporary perspectives. Hillsdale, NJ: Erlbaum.

Amsel, A. (1992). Frustration theory: An analysis of dispositional learning and memory. Cambridge: Cambridge University Press.

Amsel, A., BuRdeTte, D. R., \& LETZ, R. (1976). Appetitive learning, patterned alternation, and extinction in 10-day-old rats with nonlactating suckling as reward. Nature, 262, 816-818.

Amsel, A., Glazer, H., Lakey, J. R., MCCuller, T., \& Wong, P. T. P. (1973). Introduction of acoustic stimulation during acquisition and resistance to extinction in the normal and hippocampally-damaged rat. Journal of Comparative \& Physiological Psychology, 84, 176-186.

Amsel, A., \& RASHOTTE, M. E. (1984). Mechanisms of adaptive behavior: Clark L. Hull's theoretical papers, with commentary. New York: Columbia University Press.

Amsel, A., Rashotte, M. E., \& MacKinnon, J. R. (1966). Partial reinforcement effects within subjects and between subjects. Psychological Monographs, 80 (20, Whole No. 628).

AMsel, A., \& Roussel, J. (1952). Motivational properties of frustration: I. Effect on a running response of the addition of frustration to the motivational complex. Journal of Experimental Psychology, 43, 363-368.

AMSEl, A., \& STANTON, M. (1980). Ontogeny and phylogeny of paradoxical reward effects. In J. S. Rosenblatt, R. A. Hinde, C. Beer, \& M. Busnel (Eds.), Advances in the study of behavior (pp. 227-274). New York: Academic Press.

AMSEL, A., \& WARD, J. S. (1954). Motivational properties of frustration: II. Frustration drive stimulus and frustration reduction in selective learning. Journal of Experimental Psychology, 48, 37-47.

AMSEL, A., \& WARD, J. S. (1965). Frustration and persistence: Resistance to discrimination following prior experience with the discriminanda. Psychological Monographs, 79(4, Whole No. 597).

AMSEL, A., Wong, P. T. P., \& SCULL, J. (1971). Transfer of persistence in the domestic chick: Imprinting, punishment, and resistance to extinction of a food-reward running response. Psychonomic Science, 25, 174-176.

Angevine, J. B., JR., \& Cotman, C. W. (1981). Principles of neuroanatomy. Oxford: Oxford University Press.

BaChevalier, J., \& Mishin, M. (1984). An early and late developing system for learning and retention in infant monkeys. Behavioral Neuroscience, 98, 770-778.

BANKS, R. K. (1966). Persistence to continuous punishment following intermittent punishment training. Journal of Experimental Psychology, 71, 373-377.

BANKs, R. K. (1967). Intermittent punishment effect (IPE) sustained through changed stimulus conditions and through blocks of nonpunished trials. Journal of Experimental Psychology, 73, 456-460.

BARKER, R. G., Dembo, T., \& LEWIN, K. (1941). Frustration and regression: An experiment in young children. University of Iowa Studies in Child Welfare, 18 (Whole No. 386).

BERLYNE, D. E. (1960). Conflict, arousal, and curiosity. New York: McGraw-Hill.

BERLYNE, D. E. (1964). Structure and direction in thinking. New York: Wiley.

BitTERman, M. E. (1960). Towards a comparative psychology of learning. American Psychologist, 15, 704-712.

Bitterman, M. E. (1965). Phyletic differences in learning. American Psychologist, 20, 396-410.

Bitterman, M. E. (1975). The comparative analysis of learning. Science, 188, 699-709.

Brown, J. S., \& FARBER, I. E. (1951). Emotions conceptualized as intervening variables-with suggestions toward a theory of frustration. Psychological Bulletin, 48, 465-495.

Brown, R. T., \& Logan, F. A. (1965). Generalized partial reinforcement effect. Journal of Comparative \& Physiological Psychology, 60, 64-69.

Brown, R. T., \& WAGNER, A. R. (1964). Resistance to punishment and extinction following training with shock or nonreinforcement. Journal of Experimental Psychology, 68, 503-507. 
Burdette, D. R., Brake, S., Chen, J.-S., \& AmSel, A. (1976). Ontogeny of persistence: Immediate extinction effects in preweanling and weanling rats. Animal Learning \& Behavior, 4, 131-138.

Bush, R. R., \& Mosteller, F. (1951). A mathematical model for simple learning. Psychological Review, 58, 313-323.

CAPALDI, E. J. (1966). Partial reinforcement: A hypothesis of sequential effects. Psychological Review, 73, 459-477.

CAPALDI, E. J. (1967). A sequential hypothesis of instrumental learning. In K. W. Spence \& J. T. Spence (Eds.), The psychology of learning and motivation: Advances in research and theory (Vol. 1, pp. 67156). New York: Academic Press.

CHEN, J.-S., \& AMSEL, A. (1977). Prolonged, unsignaled, inescapable shocks increase persistence in subsequent appetitive instrumental learning. Animal Learning \& Behavior, 5, 377-385.

Chen, J.-S., \& AMsel, A. (1980a). Learned persistence at 11-12 but not at 10-11 days in infant rats. Developmental Psychobiology, 13, 481-491.

CHEN, J.-S., \& AMSEL, A. (1980b). Recall versus recognition of taste and immunization against aversive taste based on illness. Science, 209, 831-833.

CHEN, J.-S., \& AMSEL, A. (1980c). Retention under changed-reward conditions of persistence learned by infant rats. Developmental Psychology, 13, 469-480.

Chen, J.-S., Gross, K., \& Amsel, A. (1981). Ontogeny of successive negative contrast and its dissociation from other paradoxical reward effects in preweanling rats. Journal of Comparative \& Physiological Psychology, 95, 146-159.

Chen, J.-S., Gross, K., Stanton, M., \& Amsel, A. (1980). The partial reinforcement acquisition effect in preweanling and juvenile rats. Bulletin of the Psychonomic Society, 16, 239-242.

Chen, J.-S., Gross, K., Stanton, M., \& Amsel, A. (1981). Adjustment of weanling and adolescent rats to a reward condition requiring slow responding. Developmental Psychobiology, 14, 139-145.

CHILD, I. L., \& WATERHOUSE, I. K. (1952). Frustration and the quality of performance: I. A critique of the Barker, Dembo, and Lewin experiment. Psychological Review, 59, 351-362.

CRESPI, L. P. (1942). Quantitative variation of incentive and performance in the white rat. American Journal of Psychology, 55, 467. 517.

DALY, H. B. (1991). Changes in learning about aversive nonreward accounts for ontogeny of paradoxical appetitive reward effects in the rat pup: A mathematical model (DMOD) integrates results. Psychological Bulletin, 109, 325-339.

DALY, H. B., \& DALY, J. T. (1982). A mathematical model of reward and aversive nonreward: Its application in over 30 appetitive learning situations. Journal of Experimental Psychology: General, 111, 441-480.

Dollard, J., Doob, L. W., Miller, N. E., Mowrer, O. H., \& Sears, R. R. (1939). Frustration and aggression. New Haven, CT: Yale University Press.

Donin, J. A., Surridge, C. T., \& AMSEL, A. (1967). Extinction following partial delay of reward with immediate continuous reward interpolated, at 24-hour intertrial intervals. Journal of Experimental Psychology, 74, 50-53.

Eisenberger, R., Terborg, R., \& Carlson, J. (1979). Transfer of persistence across reinforced behaviors. Animal Learning \& Behavior, 7, 493-498.

ElliotT, M. H. (1928). The effect of change of reward on the maze performance of rats. University of California Publications in Psychology, 4, 19-30.

Estes, W. K. (1950). Toward a statistical theory of learning. Psychological Review, 57, 94-107.

FALLON, D. (1968). Resistance to extinction following learning with punishment of reinforced and nonreinforced licking. Journal of Experimental Psychology, 76, 550-557.

FALLON, D. (1971). Increased resistance to extinction following punishment and reward: High frustration tolerance or low frustration magnitude? Journal of Comparative \& Physiological Psychology, 77, 245-255

GRAY, J. A. (1967). Disappointment and drugs in the rat. Advancement of Science, 23, 595-605.
GRAY, J. A. (1975). Elements of two-process theory of learning. New York: Academic Press.

GraY, J. A. (1982). The neuropsychology of anxiety: An enquiry into the functions of the septo-hippocampal system. New York: Oxford University Press.

HEBB, D. O. (1980). Essay on mind. Hillsdale, NJ: Erlbaum.

Holland, P. S., \& Rescorla, R. A. (1975). The effect of two ways of devaluing the unconditioned stimulus after first- and second-order appetitive conditioning. Journal of Experimental Psychology: Animal Behavior Processes, 1, 355-363.

HoLT, L., \& GRAY, J. A. (1983). Septal driving of the hippocampal theta rhythm produces a long-term, proactive and non-associative increase in resistance to extinction. Quarterly Journal of Experimental Psychology, 35B, 97-118.

Hull, C. L. (1931). Goal attraction and directing ideas conceived as habit phenomena. Psychological Review, 38, 487-506.

Hull, C. L. (1934). The concept of the habit-family hierarchy and maze learning: Pt. 1. Psychological Review, 41, 33-54. (See also Pt. 2. Psychological Review, 1934, 41, 134-152.)

HuLL, C. L. (1938). The goal gradient hypothesis applied to some "field force" problems in young children. Psychological Review, 45, 271-299.

Hull, C. L. (1943). Principles of behavior. New York: AppletonCentury-Crofts.

Hull, C. L. (1952). A behavior system. New Haven, CT: Yale University Press.

KLEE, J. B. (1944). The relation of frustration and motivation to the production of abnormal fixations in the rat. Psychological Monographs, 56(4), 1-45.

LaChMan, R. (1960). The model in theory construction. Psychological Review, 67, 113-129.

LaWrence, D. H., \& Festinger, L. (1962). Deterrents and reinforcement. Stanford, CA: Stanford University Press.

LAWSON, R. (1965). Frustration: The development of a scientific concept. New York: Macmillan.

Letz, R., Burdette, D. R., GregG, B., Kittrell, M. E., \& Amsel, A. (1978). Evidence for a transitional period for the development of persistence in infant rats. Journal of Comparative \& Physiological Psychology, 92, 856-866.

Linden, D. R., \& HallgREN, S. O. (1973). Transfer of approach responding between punishment and frustrative nonreward sustained through continuous reinforcement. Learning \& Motivation, 4 207-217.

LoGAN, F. A. (1960). Incentive. New Haven, CT: Yale University Press.

MAIER, N. R. F. (1949). Frustration: The study of behavior without a goal. New York: McGraw-Hill.

MAIER, N. R. F. (1956). Frustration theory: Restatement and extension. Psychological Review, 63, 370-388.

MANDLER, J. (1984). Representation and recall in infancy. In M. Moscovitch (Ed.), Infant memory (pp. 75-102). New York: Plenum.

MARTIN, B. (1963). Reward and punishment associated with the same goal response: A factor in the learning of motives. Psychological Bulletin, 60, 441-451.

MCCuller, T., Wong, P. T. P., \& AMSEL, A. (1976). Transfer of persistence from fixed-ratio barpress training to runway extinction. $A n$ imal Learning \& Behavior, 4, 53-57.

Mellgren, R. L., Hoffman, D., Nation, J. R., Williams, J. D., \& Wrather, D. M. (1979). Transfer of persistence responding across motivational reward conditions. American Journal of Psychology, 92, 95-103.

MiLLER, N. E. (1944). Experimental studies of conflict. In J. M. Hunt (Ed.), Personality and the behavior disorders (Vol. 1, pp. 431-465). New York: Ronald.

MiLLER, N. E. (1948). Theory and experiment relating psychoanalytic displacement to stimulus-response generalization. Journal of $A b$ normal \& Social Psychology, 38, 89-101.

MiLLer, N. E. (1959). Liberalization of basic S-R concepts: Extensions to conflict behavior, motivation, and social learning. In S. Koch (Ed.), Psychology: A study of a science (Vol. 2, pp. 196-293). New York: McGraw-Hill 
MiLLER, N. E. (1960). Learning resistance to pain and fear: Effects of overlearning, exposure and rewarded exposure in context. Journal of Experimental Psychology, 60, 137-145.

Miller, N. E., \& MiLes, W. R. (1935). Effect of caffeine on the running speed of hungry, satiated, and frustrated rats. Journal of Comparative Psychology, 20, 397-412.

Miller, N. E., \& Miles, W. R. (1936). Alcohol and removal of reward: An analytical study of rodent maze behavior. Journal of Comparative Psychology, 21, 179-204.

Miller, N. E., \& Stevenson, S. S. (1936). Agitated behavior of rats during experimental extinction and a curve of spontaneous recovery. Journal of Comparative Psychology, 21, 205-231.

Mishkin, M., \& Petri, H. L. (1984). Memories and habits: Some implications for the analysis of learning and retention. In L. R. Squire \& N. Butters (Eds.), Neuropsychology of memory (pp. 287-296). New York: Guilford.

MOWRER, O. H. (1939). A stimulus-response analysis of anxiety and its role as a reinforcing agent. Psychological Review, 46, 553-565.

NADEL, L., \& Zola-MorGan, S. (1984). Toward the understanding of infant memory: Contributions from animal neuropsychology. In M. Moscovitch (Ed.), Infant memory (pp. 145-172). New York: Plenum.

Nation, J. R., Wrather, D. M., Mellgren, R. L., \& Spivey, M. (1980). Transfer of the partial reinforcement extinction effect between escape (shock) and appetitive (food) conditioning. Learning \& Motivation, 11, 97-116.

Rashotte, M. E., \& Amsel, A. (1968). Transfer of slow-response rituals to the extinction of a continuously rewarded response. Journal of Comparative \& Physiological Psychology, 66, 432-443.

Rashotte, M. E., \& SuRridge, C. T. (1969). Partial reinforcement and partial delay of reinforcement effects with 72-hour intertrial intervals and interpolated continuous reinforcement. Quarterly Journal of Experimental Psychology, 21, 156-161.

RATLIFF, R. G., \& Clayton, K. N. (1969). Runway extinction as a joint function of acquisition reward percentage and extinction punishment intensity. Journal of Experimental Psychology, 80, 574-576.

Rescorla, R. A., \& Solomon, R. L. (1967). Two-process learning theory: Relationships between Pavlovian conditioning and instrumental learning. Psychological Review, 74, 151-182.

ResCorLA, R. A., \& WAGNER, A. R. (1972). A theory of Pavlovian conditioning: Variations in the effectiveness of reinforcement and nonreinforcement. In A. H. Black \& W. F. Prokasy (Eds.), Classical conditioning II: Current research and theory (pp. 64-99). New York: Appleton-Century-Crofts.

ROSENZWEIG, S. (1934). Types of reaction to frustration: An heuristic classification. Journal of Abnormal \& Social Psychology, 29, 298-300.

RoSENZWEIG, S. (1944). An outline of frustration theory. In J. M. Hunt (Ed.), Personality and the behavior disorders (Vol. 1, pp. 379-388). New York: Ronald.

Rosenzweig, S., Mowrer, O. H., Haslerud, G. M., Curtis, Q. F., \& BARKER, R. G. (1938). Frustration as an experimental problem. Character \& Personality, 7, 126-160.

Ross, R. R. (1964). Positive and negative partial-reinforcement extinction effects carried through continuous reinforcement, changed motivation, and changed response. Journal of Experimental Psychology, 68, 492-502.

SCHACTER, D. L., \& Moscovitch, M. (1984). Infants, amnesics, and dissociable memory systems. In M. Moscovitch (Ed.), Infant memory (pp. 173-216). New York: Plenum.

SCHNEIRLA, T. C. (1959). An evolutionary and developmental theory of biphasic processes underlying approach and withdrawal. In M. R. Jones (Ed.), Nebraska Symposium on Motivation (pp. 1-42). Lincoln: University of Nebraska Press.

Simonov, P. V. (1974). On the role of the hippocampus in the integra- tive activity of the brain. Acta Neurobiologicae Experimentalis, 34, 33-41.

SKINNER, B. F. (1938). The behavior of organisms. New York: AppletonCentury-Crofts.

SPENCE, K. W. (1936). The nature of discrimination learning in animals. Psychological Review, 43, 427-449.

SPENCE, K. W. (1937). The differential response in animals to stimuli varying within a single dimension. Psychological Review, 44, 430-444.

SPENCE, K. W. (1940). Continuous versus non-continuous interpretations of discrimination learning. Psychological Review, 47, 271-288.

SPENCE, K. W. (1956). Behavior theory and conditioning. New Haven, CT: Yale University Press.

SPENCE, K. W. (1960). Behavior theory and learning. Englewood Cliffs, NJ: Prentice-Hall.

SPENCE, K. W. (1961). Discussion. In N. S. Kline (Ed.), Pavlovian conference on higher nervous activity (Annals of the New York Academy of Sciences, Vol. 92, pp. 813-1198). New York: New York Academy of Sciences.

SQUIRE, L. R. (1987). Memory and brain. New York: Oxford University Press.

Stanton, M. E., \& Amsel, A. (1980). Adjustment to reward reduction (but no negative contrast) in rats 11,14 , and 16 days of age. Journal of Comparative \& Physiological Psychology, 94, 446-458.

Stanton, M., Dailey, W., \& Amsel, A. (1980). Patterned (single) alternation in 11- and 14-day-old rats under various reward conditions. Journal of Comparative \& Physiological Psychology, 94, 459-471.

Sutherland, N. S. (1966). Partial reinforcement and breadth of learning. Quarterly Journal of Experimental Psychology, 18, 289-302.

Thomas, G. J. (1984). Memory: Time finding in organisms. In L. R. Squire \& N. Butters (Eds.), Neuropsychology of memory (pp. 374384). New York: Guilford.

Trapold, M. A., \& Overmier, J. B. (1972). The second learning process in instrumental learning. In A. H. Black \& W. F. Prokasy (Eds.), Classical conditioning II: Current research and theory (pp. 427-452). New York: Appleton-Century-Crofts.

VINOGRADOVA, O.S. (1975). Functional organization of the limbic system in the process of registration of information: Facts and hypotheses. In R. L. Isaacson \& K. H. Pribram (Eds.), The hippocampus: Vol. 2. Neurophysiology and behavior (pp. 1-70). New York: Plenum.

WAGNER, A. R. (1966). Frustration and punishment. In R. N. Haber (Ed.), Current research in motivation (pp. 229-238). New York: Holt, Rinehart \& Winston.

WAGNER, A. R. (1969). Frustrative nonreward: A variety of punishment? In B. A. Campbell \& R. M. Church (Eds.), Punishment and aversive behavior (pp. 157-181). New York: Appleton-Century-Crofts.

WATSON, J. B. (1919). Psychology from the standpoint of a behaviorist. Philadelphia: Lippincott.

Wilson, W., Weiss, E. J., \& Amsel, A. (1955). Two tests of the Sheffield hypothesis concerning resistance to extinction, partial reinforcement, and distribution of practice. Journal of Experimental Psychology, 50, 51-60.

WoNG, P. T. P. (1971a). Coerced approach to shock and resistance to punishment suppression and extinction in the rat. Journal of Comparative \& Physiological Psychology, 75, 82-91.

WONG, P. T. P. (1971b). Coerced approach to shock, punishment of competing responses, and resistance to extinction in the rat. Journal of Comparative \& Physiological Psychology, 76, 275-281.

Wong, P. T. P., \& AmSEL, A. (1976). Prior fixed ratio training and durable persistence in rats. Animal Learning \& Behavior, 4, 461466.

(Manuscript received September 10, 1993; revision accepted for publication November 20,1993.) 